\title{
Intentional Replacement of Dead Children in sub-Saharan Africa: Evidence from Ghana and Kenya
}

\author{
Stephen Obeng Gyimah \\ Department of Sociology \\ Queen's University \\ Kingston, Ontario, \\ Rajulton Fernando \\ Department of Sociology \\ University of Western Ontario \\ London, Ontario
}

\begin{abstract}
This paper examines whether childhood deaths elicit an explicit, conscious and intentional fertility response using the 1998 Demographic and Health Survey data for Ghana and Kenya. Using multivariate hazard models, childhood mortality experience was found to have long term fertility implications beyond the short term physiological effects. In both countries, women who have experienced childhood mortality were found to have significantly higher number of additional children than those without. The death of the first child in particular was found to be associated with the risk of a higher order birth consistent with recent findings in Cameroon. The policy implications of the findings are discussed.
\end{abstract}

Key Words: sub-Saharan Africa; Ghana; Kenya; fertility, childhood mortality; replacement hypothesis; hazard models. 
Stephen Obeng Gyimah and Fernando Rajulton

\section{Résumé}

Cet article examine si les décès d'enfants élicitent une réaction de fécondité explicite, consciente et intentionnelle à partir des données pour le Ghana et le Kenya contenues dans le Programme d'enquête démographiques et sanitaires de 1998. Au moyen de modèles de dangers multidimensionnels, on a constaté que l'expérience d'un décès d'enfant avait des conséquences à long terme sur la fécondité allant bien au-delà des effets physiologiques à court terme. Dans les deux pays, les femmes, qui avaient perdu des enfants, avaient considérablement plus d'enfants que les femmes qui n'en avaient pas perdus. On a d'ailleurs établi que le décès d'un premier enfant résultait en un plus grand ordre de naissances, ce qui a été confirmé par les dernières conclusions au Cameroun. Les répercussions en terme de politique sont traitées dans l'article.

Mots-clés : Afrique sub-saharienne, Ghana, Kenya, fécondité, mortalité infantile, hypothèse du remplacement, modèles de dangers

\section{Introduction}

Notwithstanding the extensive social scientific research, there are still unanswered questions regarding the persistence of high fertility in sub-Saharan Africa. Although fertility behaviour depends on a complexity of factors, childhood mortality is regarded as one of the most important (Preston, 1978; Montgomery and Cohen, 1998). The early proponents of the demographic transition theory, for instance, viewed declining childhood mortality as a significant impetus for the fertility decline in Western Europe. While there are divergent trends in childhood mortality in sub-Saharan Africa, the prospect of decline- a result of improvements in health and nutrition- has garnered interest in understanding its potential effect on the relatively high fertility in the region.

As Lloyd and Ivanov (1988) argue, improvement in child survival creates an environment within which the relationship between the number of children everborn and those surviving becomes predictable enough for couples to set family size goals. Couples could be expected to regulate reproductive behaviour if they are confident that the few children they have will survive into adulthood. This is particularly relevant in the context of sub-Saharan Africa where the intergenerational flow of wealth goes from children to parents as Caldwell (1982) has emphasized. Understanding the childhood mortality-fertility relationship is 
thus of practical policy relevance and goes to the heart of public intervention programs. As Wolpin (1998:74) argues, "the fertility and mortality processes are the driving forces governing population changes, so an understanding of the way they are linked is crucial for the design of policies that attempt to influence the course of population change."

While considerable research efforts have been given to understanding the physiological effects of infant deaths on subsequent fertility, less often studied but potentially of equal importance are the other pathways. This study contributes to this effort by examining the long term fertility implications of infant mortality. The major research questions are: what are the long term implications of childhood mortality on reproductive behaviour of individual women? Do childhood deaths elicit an explicit, conscious and intentional fertility response? Following the pioneering work of Kuate Defo (1998) in Cameroon, we also ask whether the death of the first child, in particular, affects the long term fertility behaviour of women. These questions will be examined using Demographic and Health Survey data from Ghana and Kenya, two of the few countries in the region currently undergoing fertility transition. Ghana and Kenya were also chosen from the standpoint of recent childhood mortality trends and the potential childbearing responses to such changes. The next section review previous work and situates the study within a theoretical context.

\section{Theoretical Framework}

The theoretical pathways through which childhood mortality affects fertility have been identified as physiological, behavioural replacement, and insurance effects (e.g., Preston, 1978; Cohen and Montgomery, 1998). Recently, LeGrand and colleagues (2003) have suggested the possibility of other pathways on the basis of qualitative research in Senegal and Zimbabwe. The physiological effect mainly operates through premature weaning and truncation of the interbirth interval following an infant death. Previous studies in diverse regions have found the risk of a subsequent birth to be higher among women with infant mortality experience than those without (Frankenberg, 1998; Mensch, 1985; Callum, Farid and Moussa, 1988). While the physiological effect is more pronounced in populations with extensive breastfeeding patterns such as those of sub-Saharan Africa (Grummer-Strawn, Stupp and Mei, 1998), its magnitude tends to attenuate as a society undergoes transition during which a conscious effort is made to space and limit births(Gyimah and Fernando, 2002).

The present study goes beyond the short-term physiological effect by examining the long term impact of infant death on fertility. The question worth answering is whether the survival statuses of previous children significantly alters the risk 
Stephen Obeng Gyimah and Fernando Rajulton

of birth of a higher order. From a theoretical perspective, the long term impact can be couched within the behavioral response hypothesis. In its usual rendition, the behavioral replacement hypothesis refers to deliberate efforts couples make to bear another child in the hope of replacing the lost one. In most empirical studies, replacement behavior is explored by examining the influence of previous infant deaths on contraceptive use, completed fertility, or parity progression ratios. These studies attest that the tendency to move to higher parities increases with the number of dead children. Women with childhood mortality experience tended to have a significantly higher number of children ever born than their counterparts without such experience (e.g., Gyimah, 2001; Nyarko, Madise and Diamond, 1999; Montgomery and Cohen, 1998).

Again, within the framework of the behavioral effect, women with child loss experience are less likely to use contraception but more likely to discontinue if they are already using. A number of empirical studies in sub-Saharan Africa and elsewhere tend to corroborate this hypothesis (see, e.g., Chowdhury, Fauvean and Aziz, 1992; Oheneba- Sakyi and Takyi, 1997). Among Ghanaian women, for example, Nyarko, Madise and Diamond (1999) observed that mothers with previous child death were 57 percent less likely to use contraception compared with mothers with no childhood mortality experience. In rural Bangladesh, Rahman (1998) also found that the risk of discontinuing contraception was 92 percent higher among couples who have experienced child deaths. These findings obviously point to a deliberate and conscious effort among women with childhood mortality experience.

To understand the intentional replacement behavior in this study, we examine the survival statuses of earlier births on the risk of a higher order birth1 The model on the risk of a fourth birth (outcome variable), for instance, includes the survival status of the first, second, and third children (main independent variables) together with other theoretically relevant covariates. If a significant relationship is found between the survival status of previous births and the risk of birth of higher order, such effects cannot be attributed to physiological factors associated with infant deaths but to long term volitional replacement behavior. This is primarily because the physiological effect of breastfeeding truncation associated with the death of infant $I$ can only affect the timing of birth of child $I+1$ but not $I+2$.

Previous research has also placed less emphasis on the possibility of differential replacement behaviour on the basis of the parity of the dead child. This is particularly relevant in the context of sub-Saharan Africa where the first child is deemed special and his/her arrival is often heralded by a cluster of ceremonial events (Kuate Defo, 1998). Given this, the death of the first born in childhood is usually regarded as a bad omen for the reproductive life of the woman and 
therefore enormous social pressure is often put on the couple to have as many children as possible. Following Kuate Defo, we test whether the death of the first child in particular has a significant long term effect on a woman's fertility behaviour.

\section{Methodology}

The 1998 Demographic and Health Surveys (DHS) for Ghana and Kenya were used for this study. The surveys were conducted by Macro International in conjunction with the Ghana Statistical Service and Kenya's National Council for Population and Development. The surveys are nationally representative, stratified, self-weighting probability samples of women in the reproductive ages of 15 to 49 years. In addition to country specific modules, there are standard core questionnaires on socio-economic, demographic and health indicators, thus making cross-national comparisons easier. Data quality is a concern to any study that uses retrospective data to examine the timing of events as this paper does. Although there are non sampling errors on some age-related variables in the DHS, several studies suggest the data compare favourably with other large scale surveys such as the World Fertility Survey (Gage, 1995). Like other retrospective surveys, however, there is the likelihood of recall bias and selective reporting and this is a limitation that needs to be recognized.

Since we examine the influence of infant deaths on the risk of subsequent births, individual women with at least one birth constitute the unit of analysis. To explore the long term effects of childhood deaths, we focus on two dependent measures, namely the total number of children ever born and the risk of high order birth defined by the duration between successive births. Examining the timing of births with retrospective data introduces the problem of right censoring caused by the incomplete experience of the event studied (Allison, 1995). Censored cases require special treatment in estimating exposure time and for this reason normal regression procedures are unsuitable. The appropriate techniques in the presence of censoring come under the rubric of survival analysis, the oldest being the non-parametric life table technique. Censoring is assumed to occur uniformly over the interval such that on average censored individuals are at risk of experiencing the event at the mid point of the interval. However, while the life table can be used to estimate survival time, it does not readily allow one to control for theoretically meaningful variables that affect survival time in a multivariate context. The best one could do under such circumstances is to estimate survival probabilities for selected heterogenous groups. The results will, however, be unreliable because of the disaggregation of the sample into smaller heterogeneous groups of interest. 
Stephen Obeng Gyimah and Fernando Rajulton

Hazard models combine aspects of the life table and multiple regression techniques and allow the risk to depend on factors that describe heterogeneity. These models are used when the outcome of interest is duration until the occurrence of some event. Cox's (1972) proportional hazard model is used to examine the long term effects of infant deaths on fertility. Unlike parametric models, the Cox model does not make any assumption about the distribution of the timing function and therefore appropriate for events whose empirical distribution is unknown. The model is based on the assumption that the ratio of the hazard functions of two individuals is constant throughout the period of observation. The basic form of the model is given as

$$
\lambda(t)=\lambda_{0}(t) \exp \left(\beta_{i} x_{i}+\cdots+\beta_{k} x_{k}\right)
$$

where $\lambda_{i}(t)$ is the risk of birth at time $t$ for an individual, $\lambda_{0}(t)$ is the baseline hazard at duration $t, \beta^{\prime} s$ are the regression coefficient estimated by Partial-Likelihood method and $x^{\prime} s$ are time-invariant theoretically relevant variables. The ratio of the hazard is therefore independent of duration and indicative of the relative risk of a given event occurring among individuals

characterised by time invariant covariates vectors $x_{i}$ and $x_{j}$. The proportionality assumption can be examined by plotting the log-minus log on survival time. Using this model, we estimated the relative risks of higher order births controlling for the survival status of previous children and other theoretically relevant variables. For a more intuitive understanding, the coefficients $\left(\beta\right.$ ) have been transformed by exponentiation $\left(e^{\beta}\right)$ and are interpreted as relative risk or hazard ratios. The relative risk is a statistical estimate of the extent to which specific attributes predispose women to differential risk of births. A hazard ratio significantly greater than one indicates that women with this attribute have a higher risk of birth than women in the reference category. Conversely, if the relative risk is less than one, women with this attribute are expected to have a significantly lower risk of birth than women in the reference category.

\section{Control variables}

Besides childhood mortality, there are a number of demographic, socioeconomic, and socio-cultural factors that are known to affect fertility (see Table 1 for distribution). The cross-sectional nature of our data requires the use of current status information which implicitly requires a Markovian assumption of time independence when this is clearly not the case for all the variables. This is 
a limitation that needs to be recognized. The demographic controls include birth cohort, age at first marriage and the duration of the previous birth interval. Birth cohort, measured by a series of dummy variables, is indicative of socio-cultural and politico-economic contexts that shape the life course experiences of individual women. Given that women in the younger cohorts became adolescents in a period of a more egalitarian gender roles, efficient contraceptives and higher female enrolments in formal education, we expect them to have a lower risk of births compared to the older cohorts. Age at first marriage is also important in fertility studies because of its inverse relation to the exposure to the risk of conception (Westoff, 1992). Women who marry early are expected to have a higher risk of births than their counterparts whose first marriage occurs late.

Further, the length of the preceding birth interval can be considered a proxy for the combined effects of proximate variables such as length of voluntary and involuntary abstinence and effective contraceptive use, among others. To capture these differences which might account for differentials in the risk of subsequent births, the length of the preceding interval $t$ (defined as the duration between successive births) is introduced as a categorical covariate (under 19 months, 19-36 months, above 36 months) in the transition to the next parity. Given the relationship between birth interval and child survival as demonstrated in previous research, shorter preceding intervals are hypothesized to associate with a higher risk of a subsequent birth.

Turning to the socio-economic controls, there is considerable empirical evidence that associates urban residence and high levels of maternal education with lower risk of births. The pathways through which these happen have been explained through late age at marriage, high contraceptive use, and labor force participation (Martin, 1995; Oheneba- Sakyi and Takyi, 1997; Gyimah, 2001). In this study, maternal education is categorized into less than secondary and at least secondary. In line with previous research, we expect the risk of subsequent births to be lower among secondary educated women compared to others. Also, fertility in urban areas of sub-Saharan Africa tends to be substantially lower than what prevails in rural areas, a difference of about 1.8 births per woman (Cohen, 1993). This perhaps sheds light on the differential influence of the socioeconomic and cultural factors on reproduction in rural and urban settings. Urban residents are thus hypothesized to have a lower risk of subsequent birth. 


\section{Stephen Obeng Gyimah and Fernando Rajulton}

Table 1

Percent Distribution of the Covariates associated with the Risk of Births

Ghana and Kenya: 1998

\begin{tabular}{|c|c|c|c|c|c|c|c|}
\hline \multirow{2}{*}{\multicolumn{2}{|c|}{ Covariates }} & \multicolumn{3}{|c|}{ Ghana } & \multicolumn{3}{|c|}{ Kenya } \\
\hline & & $\begin{array}{l}\text { Second } \\
\text { Birth }\end{array}$ & $\begin{array}{l}\text { Third } \\
\text { Birth }\end{array}$ & $\begin{array}{c}\text { Fourth } \\
\text { Birth }\end{array}$ & $\begin{array}{l}\text { Second } \\
\text { Birth }\end{array}$ & $\begin{array}{l}\text { Third } \\
\text { Birth }\end{array}$ & $\begin{array}{c}\text { Fourth } \\
\text { Birth }\end{array}$ \\
\hline \multicolumn{8}{|c|}{ Sex Composition of Surviving Children } \\
\hline All girls & & 47.30 & 15.80 & 25.00 & 50.30 & 38.50 & 49.00 \\
\hline Mixed & & -- & 33.80 & 55.00 & -- & 41.80 & 19.00 \\
\hline All boys & & 52.70 & 42.00 & 20.00 & 49.70 & 19.60 & 25.00 \\
\hline \multicolumn{8}{|l|}{ Birth Cohort } \\
\hline After 1972 & & 14.00 & 6.20 & 2.50 & 18.40 & 9.60 & 4.10 \\
\hline $1962-1972$ & & 44.00 & 15.80 & 38.30 & 46.00 & 47.00 & 44.70 \\
\hline Before 1962 & & 42.00 & 33.80 & 59.00 & 36.60 & 43.40 & 49.00 \\
\hline \multicolumn{8}{|l|}{ Age at First Birth } \\
\hline Under 21 years & & 58.00 & 61.00 & 63.20 & 67.30 & 70.00 & 72.00 \\
\hline Over 21 years & & 42.00 & 39.00 & 36.80 & 32.70 & 30.00 & 28.00 \\
\hline \multicolumn{8}{|l|}{ Education } \\
\hline Secondary education & & 36.50 & 32.80 & 30.00 & 22.70 & 20.00 & 16.60 \\
\hline Below Secondary & & 63.50 & 67.20 & 70.00 & 77.30 & 80.00 & 83.40 \\
\hline \multicolumn{8}{|l|}{ Current Residence } \\
\hline Urban & & 27.30 & 25.30 & 22.60 & 14.50 & 13.00 & 10.00 \\
\hline Rural & & 72.70 & 74.70 & 77.40 & 85.50 & 87.00 & 90.00 \\
\hline \multicolumn{8}{|l|}{ Ethnicity } \\
\hline GHANA & KENYA & & & & & & \\
\hline $\mathrm{Ga}$ & Kikuyu & 6.40 & 5.90 & 5.50 & 15.30 & 14.00 & 12.70 \\
\hline Ewe & Kisii & 12.40 & 11.40 & 11.30 & 7.30 & 7.70 & 8.00 \\
\hline Mole-Daghani & Kalejin & 32.60 & 34.60 & 36.40 & 17.60 & 18.40 & 19.30 \\
\hline Others & Luhya & 3.60 & 4.00 & 4.00 & 15.50 & 14.90 & 15.30 \\
\hline Akan & Others & 45.00 & 44.00 & 42.70 & 45.00 & 44.70 & 44.50 \\
\hline \multicolumn{8}{|l|}{ Marital Union } \\
\hline Polygynous & & 25.00 & 26.60 & 27.80 & 26.40 & 26.50 & 27.00 \\
\hline Monogamous & & 62.00 & 61.00 & 60.00 & 63.50 & 64.00 & 64.10 \\
\hline Not married & & 13.00 & 12.40 & 12.20 & 10.10 & 9.50 & 9.00 \\
\hline \multicolumn{8}{|l|}{ Spouse's Residence } \\
\hline Co-residence & & 64.00 & 66.50 & 67.00 & 63.20 & 65.00 & 66.00 \\
\hline Lives elsewhere & & 36.00 & 33.50 & 33.00 & 36.80 & 35.00 & 34.00 \\
\hline \multicolumn{8}{|c|}{ Length of Preceding Birth Interval } \\
\hline Under 19 months & & 8.20 & 8.30 & 8.40 & 17.50 & 28.00 & 16.00 \\
\hline 19-36 months & & 48.00 & 49.00 & 52.00 & 53.40 & 56.60 & 56.00 \\
\hline Above 36 months & & 45.00 & 42.00 & 36.40 & 29.00 & 15.40 & 28.00 \\
\hline TOTAL & & 2757 & 2123 & 1609 & 4618 & 3626 & 2849 \\
\hline
\end{tabular}


There are also a number of socio-cultural factors that influence reproduction in sub- Saharan Africa (Lesthaeghe, 1989). Among these are ethnic-specific practices, norms and values that capture both the observable and unobservable behavioral and cultural factors affecting reproductive behaviour in the region. In Ghana, four main ethnic groups (Akans, Mole-Dagbanis, Gas, Ewes) and a residual class are identified while in Kenya, the Kikuyus are differentiated from the Kisii, Luhya, Kalenjin and Others. Given the fact that the Kikuyus tend to be more educated and urbanized than others in Kenya, we expect to find longer transition times among them compared with the other ethnic groups. In Ghana, the Ewes and Mole-Dagbanis are hypothesized to have a lower risk of subsequent birth than the Akans because of their relatively long post-partum abstinence period and patrilocal residence.

Turning to marriage, research in sub-Saharan Africa suggests it is often a sequential process involving several steps (Meekers, 1992). For this reason, we included both the married and unmarried women in the sample. Because married couples tend to be more secure in their commitment towards family building than the unmarried, we expect the risk of births to be higher among married women. However, given the complexity of the relationship between the type of marital union and fertility in sub-Saharan Africa at the individual level (see Ezeh, 1997), married women were further classified into either monogamous or polygynous unions. Following Garenne and van de Walle (1989), we expect women in polygynous union to have a lower risk of birth than those in monogamous unions. The premise is that not only do polygynous wives tend to marry older men whose fertility is much lower but they also spend more time away from their spouses than their monogamous counterparts.

Lastly, the sex composition of surviving children has been found to have a significant bearing on fertility particularly in cultures that accord special privileges to sons. While most sub-Saharan African societies do not show a conscious preference for sons compared with those in Asia, some recent studies in the region allude to son preference (e.g., Kuate Defo, 1998; Nyarko et al., 1999; Mace, 1996). On the basis of these recent findings, women whose surviving children are all daughters are expected to have a higher risk of subsequent births than their counterparts whose surviving children are males.

\section{Findings and Discussion}

Preliminary results of the mean number of subsequent births to women at various attained parities by childhood mortality experience are presented in Table 2. The analysis was done separately for all women and older women (above 37 years at the time of the survey). At each attained parity, women are 
Stephen Obeng Gyimah and Fernando Rajulton

grouped according to their prior experience with childhood mortality on the basis of which we estimated the mean number of subsequent births. Women who have given birth to two children, for example, are classified into three categories on the basis of past infant mortality experience- those with one prior infant death (1); those with two infant deaths(2); and those without any prior infant death (0). The results in Table 2 (column titled \# of women) suggest that among 2798 Ghanaian women with two children, 14 percent (399) had experienced one infant death, 1.3 percent (39) had two deaths while the majority (85 percent) have not had any infant death. Among the 1642 women with at least four births, only 72 percent (1183) had not experienced infant deaths and about 6 percent (98) have experienced at least two deaths. The proportion of women with infant mortality experience tends to be slightly higher at all parities in Kenya, perhaps reflecting recent mortality reversals.

Turning to the relationship between prior infant deaths and the mean number of subsequent births, the results in Table 2 (column titled \# of subsequent births) also demonstrate that women with childhood mortality experience tend to have a larger number of subsequent births than those with no child deaths irrespective of the attained parity. Among Ghanaian women with first births, for example, those who lost the child before the second birth went on to have 3.72 additional children as against 2.70 among those whose child survived till the second birth. Similarly, Ghanaian women with no prior infant death up till the fourth birth had 1.73 additional children while their counterparts with no surviving children had 6.0 additional children, a difference of about 4.30 children.

A parallel pattern is seen among Kenyan women where at the third parity, for instance, those without any infant death proceeded to have 2.47 additional children while those with no surviving children had about 4.50 additional children. At all attained parities, the results corroborate the hypothesis that women who have had infant deaths tend to have a higher number of subsequent births than their counterparts without any or with fewer infant deaths. While this pattern provides some evidence of a deliberate replacement behaviour, replacement tends to be incomplete suggesting that the number of additional births necessitated by child mortality do not perfectly match the number of dead children.

\section{Multivariate hazard models}

To unravel the net effect of infant death on the risk of higher order births, the demographic, socio-economic and socio-cultural factors are controlled in the multivariate hazard models presented in Tables 3 and 4 . For the risk of third and fourth births, three models were built hierarchically: Model 1 controlling for 
Intentional Replacement of Dead Children in Sub-Saharan Africa:

Evidence from Ghana and Kenya

Table 2

Mean Number of Subsequent Births to Women of Various Attained Parities by Child Mortality

Experience at that Parity, Ghana and Kenya: 1998

\begin{tabular}{|c|c|c|c|c|c|c|c|c|}
\hline \multirow{3}{*}{$\begin{array}{c}\text { Number of Deaths } \\
\text { at Each Attained } \\
\text { Parity }\end{array}$} & \multicolumn{4}{|c|}{ All Women } & \multicolumn{4}{|c|}{ Women Above 37 Years } \\
\hline & \multicolumn{2}{|c|}{ Ghana } & \multicolumn{2}{|c|}{ Kenya } & \multicolumn{2}{|c|}{ Ghana } & \multicolumn{2}{|c|}{ Kenya } \\
\hline & $\begin{array}{l}\text { No. of } \\
\text { subsequent } \\
\text { births }\end{array}$ & $\begin{array}{l}\text { No. of } \\
\text { women }\end{array}$ & $\begin{array}{l}\text { No. of } \\
\text { subsequent } \\
\text { births }\end{array}$ & $\begin{array}{l}\text { No. of } \\
\text { women }\end{array}$ & $\begin{array}{l}\text { No. of } \\
\text { subsequent } \\
\text { births }\end{array}$ & $\begin{array}{l}\text { No. of } \\
\text { women }\end{array}$ & $\begin{array}{l}\text { No. of } \\
\text { subsequent } \\
\text { births }\end{array}$ & $\begin{array}{l}\text { No. of } \\
\text { women }\end{array}$ \\
\hline First Parity & & 3499 & & 5717 & & 1140 & & 1657 \\
\hline 0 & 2.70 & 3192 & 3.01 & 5281 & 4.62 & 1029 & 5.44 & 1511 \\
\hline 1 & 3.72 & 307 & 4.00 & 430 & 5.31 & 111 & 6.74 & 146 \\
\hline Difference $(0,1)$ & 1.02 & & 1.26 & & 0.69 & & 1.13 & \\
\hline Second Parity & & 2798 & & 4618 & & 1097 & & 1611 \\
\hline 0 & 2.36 & 2365 & 2.71 & 4029 & 3.76 & 928 & 3.55 & 1932 \\
\hline 1 & 2.96 & 399 & 3.45 & 519 & 4.41 & 150 & 5.07 & 188 \\
\hline 2 & 3.74 & 39 & 4.41 & 70 & 5.11 & 19 & 6.00 & 31 \\
\hline Difference $(0,1)$ & 0.60 & & 0.74 & & 0.65 & & 2.17 & \\
\hline Difference $(0,2)$ & 1.38 & & 1.70 & & 1.35 & & 2.45 & \\
\hline Third Parity & & 2170 & & 3626 & & 1079 & & 1544 \\
\hline 0 & 2.00 & 1961 & 2.47 & 2978 & 2.90 & 811 & 3.71 & 1277 \\
\hline 1 & 2.51 & 398 & 3.04 & 524 & 3.60 & 181 & 4.87 & 218 \\
\hline 2 & 2.85 & 71 & 3.56 & 108 & 3.80 & 80 & 5.26 & 39 \\
\hline 3 & 4.70 & 10 & 4.50 & 16 & 5.30 & 7 & 5.50 & 10 \\
\hline Difference $(0,1)$ & 0.51 & & 0.27 & & 0.70 & & 1.16 & \\
\hline Difference $(0,2)$ & 0.85 & & 1.09 & & 1.00 & & 1.55 & \\
\hline Difference $(0,3)$ & 2.70 & & 2.03 & & 2.40 & & 1.79 & \\
\hline Fourth Parity & & 1642 & & 2849 & & 915 & & 1429 \\
\hline 0 & 1.73 & 1183 & 2.14 & 2201 & 2.34 & 673 & 3.0 & 1113 \\
\hline 1 & 2.15 & 361 & 2.71 & 483 & 3.00 & 187 & 3.9 & 244 \\
\hline 2 & 2.50 & 80 & 3.17 & 127 & 3.51 & 11 & 4.6 & 55 \\
\hline 3 & 3.06 & 16 & 3.20 & 31 & 3.60 & 2 & 4.4 & 12 \\
\hline 4 & 6.00 & 2 & 4.14 & 7 & 6.00 & & 8.6 & 5 \\
\hline Difference $(0,1)$ & 0.42 & & 0.57 & & 0.66 & & 0.9 & \\
\hline Difference $(0,2)$ & 0.77 & & 1.03 & & 1.17 & & 1.6 & \\
\hline Difference $(0,3)$ & 1.33 & & 1.06 & & 1.26 & & 1.4 & \\
\hline Difference $(0,4)$ & 4.27 & & 2.27 & & 3.66 & & 5.6 & \\
\hline
\end{tabular}




\section{Stephen Obeng Gyimah and Fernando Rajulton}

Table 3

Cox Model of Covariates Associated with Third Births, Ghana and Kenya: 1998

\begin{tabular}{|c|c|c|c|c|c|c|}
\hline \multirow{2}{*}{ Covariates } & \multicolumn{3}{|c|}{ Ghana } & \multicolumn{3}{|c|}{ Kenya } \\
\hline & Model 1 & Model 2 & Model 3 & Model 1 & Model 2 & Model 3 \\
\hline \multicolumn{7}{|l|}{ Status of Child } \\
\hline First child died in infancy & $1 . .35 * * *$ & $1.28^{* * *}$ & $1.32 * * *$ & $1.22 * * *$ & $1.12^{*}$ & $1.16^{* *}$ \\
\hline Survived (reference) & $\mid 1.00$ & 1.00 & 1.00 & 1.00 & 1.00 & 1.00 \\
\hline Second child died in infancy & $2.48^{* * *}$ & $1.80^{* * *}$ & $1.93^{* * *}$ & $2.19 * * *$ & $1.67 * * *$ & $1.72^{* * *}$ \\
\hline Survived (reference) & & 1.00 & 1.00 & 1.00 & 1.00 & 1.00 \\
\hline \multicolumn{7}{|l|}{ Birth Cohort } \\
\hline After 1972 & & $0.09 * * *$ & $0.11^{* * *}$ & & $0.11 * * *$ & $0.14^{* * *}$ \\
\hline $1962-1972$ & & $0.60^{* * *}$ & $0.59^{* * *}$ & & $0.70^{* * *}$ & $0.69^{* * *}$ \\
\hline Before 1962 (reference) & & 1.00 & 1.00 & & 1.00 & 1.00 \\
\hline \multicolumn{7}{|l|}{ Age at First Marriage } \\
\hline Under 21 years & & $1.72 * * *$ & $1.60^{* * *}$ & & $2.04 * * *$ & $1.64 * * *$ \\
\hline Over 21 years (reference) & & 1.00 & 1.00 & & 1.00 & 1.00 \\
\hline \multicolumn{7}{|l|}{ Education } \\
\hline Secondary education & & $0.61^{* * *}$ & $0.62 * * *$ & & $0.82 * * *$ & $0.78^{* * *}$ \\
\hline Below Secondary (reference) & & 1.00 & 1.00 & & 1.00 & 1.00 \\
\hline \multicolumn{7}{|l|}{ Residence } \\
\hline Urban & & $0.79 * * *$ & $0.83^{* * *}$ & & $0.66 * * *$ & $0.74 * *$ \\
\hline Rural (reference) & & 1.00 & 1.00 & & 1.00 & 1.00 \\
\hline \multicolumn{7}{|l|}{ Ethnicity } \\
\hline GHANA & & & & & & \\
\hline Kikuyu & & & 1.00 & & & $0.89^{*}$ \\
\hline Kisii & & & 0.91 & & & 1.01 \\
\hline Mole-Daghani & & & $0.75^{* * *}$ & & & $1.14^{* *}$ \\
\hline Others & & & 1.04 & & & 1.14 \\
\hline Akan (reference) & & & 1.00 & & & 1.00 \\
\hline \multicolumn{7}{|l|}{ Type of Marital Union } \\
\hline Polygynous & & & $0.84^{*}$ & & & 0.93 \\
\hline Not married & & & $0.80^{* * *}$ & & & $0.64 * * *$ \\
\hline Monogamous (reference) & & & 1.00 & & & 1.00 \\
\hline \multicolumn{7}{|l|}{ Spouse's Residence } \\
\hline Co-residence & & & $1.20^{* * *}$ & & & 0.97 \\
\hline Lives elsewhere (reference) & & & 1.00 & & & 1.00 \\
\hline \multicolumn{7}{|l|}{ Length of Preceding Birth Interval } \\
\hline Under 19 months & & & 1.07 & & & $1.19^{* * *}$ \\
\hline Above 36 months & & & $0.55^{* * *}$ & & & $0.49^{* * *}$ \\
\hline $19-36$ months & & & 1.00 & & & 1.00 \\
\hline \multicolumn{7}{|l|}{ Sex Composition of Surviving Children } \\
\hline All girls & & & $1.41^{* * *}$ & & & $1.28^{* * *}$ \\
\hline Mixed & & & $1.32 * * *$ & & & $1.26^{* * *}$ \\
\hline All boys & & & 1.00 & & & 1.00 \\
\hline -2 Log Likelihood & 32882 & 31605 & 31304 & 59392 & 56932 & 56357 \\
\hline Chi-Square & 125 & 1403 & 1704 & 137 & 2547 & 3172 \\
\hline Degrees of Freedom & 2 & 7 & 18 & 2 & 7 & 18 \\
\hline Significance & 0.000 & 0.000 & 0.000 & 0.000 & 0.000 & 0.000 \\
\hline
\end{tabular}


Intentional Replacement of Dead Children in Sub-Saharan Africa:

Evidence from Ghana and Kenya

Table 4

A Cox Model of Covariates Associated with the Risk of Fourth Births, Ghana and Kenya: 1998

\begin{tabular}{|c|c|c|c|c|c|c|}
\hline \multirow[b]{3}{*}{ Covariates } & \multicolumn{3}{|c|}{ Ghana } & \multicolumn{3}{|c|}{ Kenya } \\
\hline & \multicolumn{3}{|c|}{ Hazard Ratios } & \multicolumn{3}{|c|}{ Hazard Ratios } \\
\hline & Model 1 & Model 2 & Model 3 & Model 1 & Model 2 & Model 3 \\
\hline \multicolumn{7}{|l|}{ Status of Child } \\
\hline First child died in infancy & $\mid 1.32 * * *$ & $1.29^{* * *}$ & $1.60^{* * *}$ & $\mid 1.24 * * *$ & $1.15^{*}$ & $1.11^{*}$ \\
\hline Survived (reference) & 1.00 & 1.00 & 1.00 & $\mid 1.00$ & 1.00 & 1.00 \\
\hline Second child died in infancy & $\mid 1.72^{* * *}$ & $1.49^{* * *}$ & $1.42 *$ & |1.46*** & $1.14 !$ & 1.04 \\
\hline Survived (reference) & $\mid 1.00$ & 1.00 & 1.00 & $\mid 1.00$ & 1.00 & 1.00 \\
\hline Third child died in infancy & | $3.14^{* * *}$ & $1.89^{* * *}$ & $1.94^{* * *}$ & $2.88^{* * *}$ & $1.81^{* * *}$ & $1.62^{* * *}$ \\
\hline Survived (reference) & 1.00 & 1.00 & 1.00 & $\mid 1.00$ & 1.00 & 1.00 \\
\hline \multicolumn{7}{|l|}{ Birth Cohort } \\
\hline After 1972 & & $0.03^{* * *}$ & $0.05^{* * *}$ & & $0.04 * * *$ & $0.10^{* * *}$ \\
\hline $1962-1972$ & & $0.40^{* * *}$ & $0.45^{* * *}$ & & $0.55^{* * *}$ & $0.62^{* * *}$ \\
\hline Before 1962 (reference) & & 1.00 & 1.00 & & 1.00 & 1.00 \\
\hline \multicolumn{7}{|l|}{ Age at First Marriage } \\
\hline Under 21 years & & $2.02 * * *$ & $1.76^{* * *}$ & & $2.15^{* * *}$ & $1.60^{* * *}$ \\
\hline Over 21 years (reference) & & 1.00 & 1.00 & & 1.00 & 1.00 \\
\hline \multicolumn{7}{|l|}{ Education } \\
\hline Secondary education & & $0.58^{* * *}$ & $0.68^{* * *}$ & & $0.72^{* * *}$ & $0.75^{* * *}$ \\
\hline Below Secondary (reference) & & 1.00 & 1.00 & & 1.00 & 1.00 \\
\hline Residence & & & & & & \\
\hline Urban & & $0.71 * * *$ & $0.75^{* *}$ & & $0.53 * * *$ & $0.66^{* *}$ \\
\hline Rural (reference) & & 1.00 & 1.00 & & 1.00 & 1.00 \\
\hline Ethnicity & & & & & & \\
\hline GHANA & & & & & & \\
\hline Kikuyu & & & 1.00 & & & $0.87^{*}$ \\
\hline Kisii & & & 0.96 & & & $1.15^{*}$ \\
\hline Mole-Daghani & & & $0.90^{*}$ & & & $1.24^{* * *}$ \\
\hline Others & & & 0.97 & & & 1.07 \\
\hline Akan (reference) & & & 1.00 & & & 1.00 \\
\hline Type of Marital Union & & & & & & \\
\hline Polygynous & & & 0.97 & & & 0.99 \\
\hline Not married & & & $0.80^{* * *}$ & & & $0.93 *$ \\
\hline Monogamous (reference) & & & 1.00 & & & 1.00 \\
\hline Spouse's Residence & & & & & & \\
\hline Co-residence & & & $1.32^{* * *}$ & & & $1.12^{*}$ \\
\hline Lives elsewhere (reference) & & & 1.00 & & & 1.00 \\
\hline Length of Preceding Birth Interval & & & & & & \\
\hline Under 19 months & & & $1.32^{* * *}$ & & & $1.10^{*}$ \\
\hline Above 36 months & & & $0.42^{* * *}$ & & & $0.45^{* * *}$ \\
\hline $19-36$ months & & & 1.00 & & & 1.00 \\
\hline Sex Composition of Surviving Children & & & & & & \\
\hline All girls & & & $1.65^{* * *}$ & & & $3.17^{* * *}$ \\
\hline Mixed & & & $1.61^{* * *}$ & & & $2.66^{* * *}$ \\
\hline All boys & & & 1.00 & & & 1.00 \\
\hline -2 Log Likelihood & 25202 & 23797 & 23335 & 47166 & 44433 & 43317 \\
\hline Chi-Square & 285 & 1592 & 2054 & 212 & 2944 & 4061 \\
\hline Degrees of Freedom & 3 & 8 & 19 & 3 & 8 & 19 \\
\hline Significance & 0.000 & 0.000 & 0.000 & 0.000 & 0.000 & 0.000 \\
\hline
\end{tabular}


only the survival statuses of all previous children; Model 2 controlling for the survival variables as well as the demographic and socio-economic variables; Model 3 controlling for all the variables. The log likelihood ratios suggest significant improvements in fit from across models for both samples.

The results invariably substantiate the argument that infant deaths indeed have substantial long term impact on fertility behavior. The death of the first child, for instance, tends to associate with a higher risk of a third birth in both countries, the effects being robust and virtually unchanged across models. From Model 3, the risk of a third birth is 32 percent higher among Ghanaian women who lost their first child compared with those whose first child survived. A similar pattern can be seen among Kenyan women where the death of the first child increases the risk of a third birth by 16 percent. Further evidence on the long term effects of childhood deaths on the risk of a higher order birth is demonstrated in Table 4. The results also demonstrate that the death of previous children is significantly linked with a higher risk of a fourth birth, the effect being robust across models. Compared with women whose first child survived, the risk of a fourth birth is 60 percent higher among Ghanaian women who lost their first child and 11 percent higher among their Kenyan counterparts as illustrated in Model 3. Similarly, the risk of a fourth birth is 42 percent higher for women who lost their second child in Ghana and 4 percent higher among their Kenyan counterparts although the effects are not significant in the latter case.

The association between the survival status of previous children and the risk of higher order births as demonstrated in the preceding discussion cannot be simply due to physiological factors but points in the direction of a behavioural replacement. It is also worth noting that while the death of the first child associates with a higher risk of subsequent births, that of the second child is less influential in both countries (see the risk of fourth births in Table 4). This confirms Kuate Defo's work in Cameroon and suggests that the death of the first child has a special bearing on fertility patterns.

We also examine the number of previous infant deaths (but not limited to the status index child) on the risk of third and fourth births in a multivariate context (Table 5). For the risk of each birth, we present two models: Model 1 controls for only the number of previous infant deaths while Model 2 includes all the covariates. On the basis of previous infant mortality experience, women at the risk of third birth are categorized into three groups (no dead children, one dead child; two dead children) while those at the risk of a fourth birth are classified into four (no dead children, one dead child; two dead children; three dead children). The results suggest that women with high number of infant deaths have higher risk of subsequent birth. Compared with Ghanaian women who 
Intentional Replacement of Dead Children in Sub-Saharan Africa: Evidence from Ghana and Kenya

Table 5

A Cox Model on the Risk of Births by Number of Surviving Children and Other Covariates, Ghana and Kenya: 1998

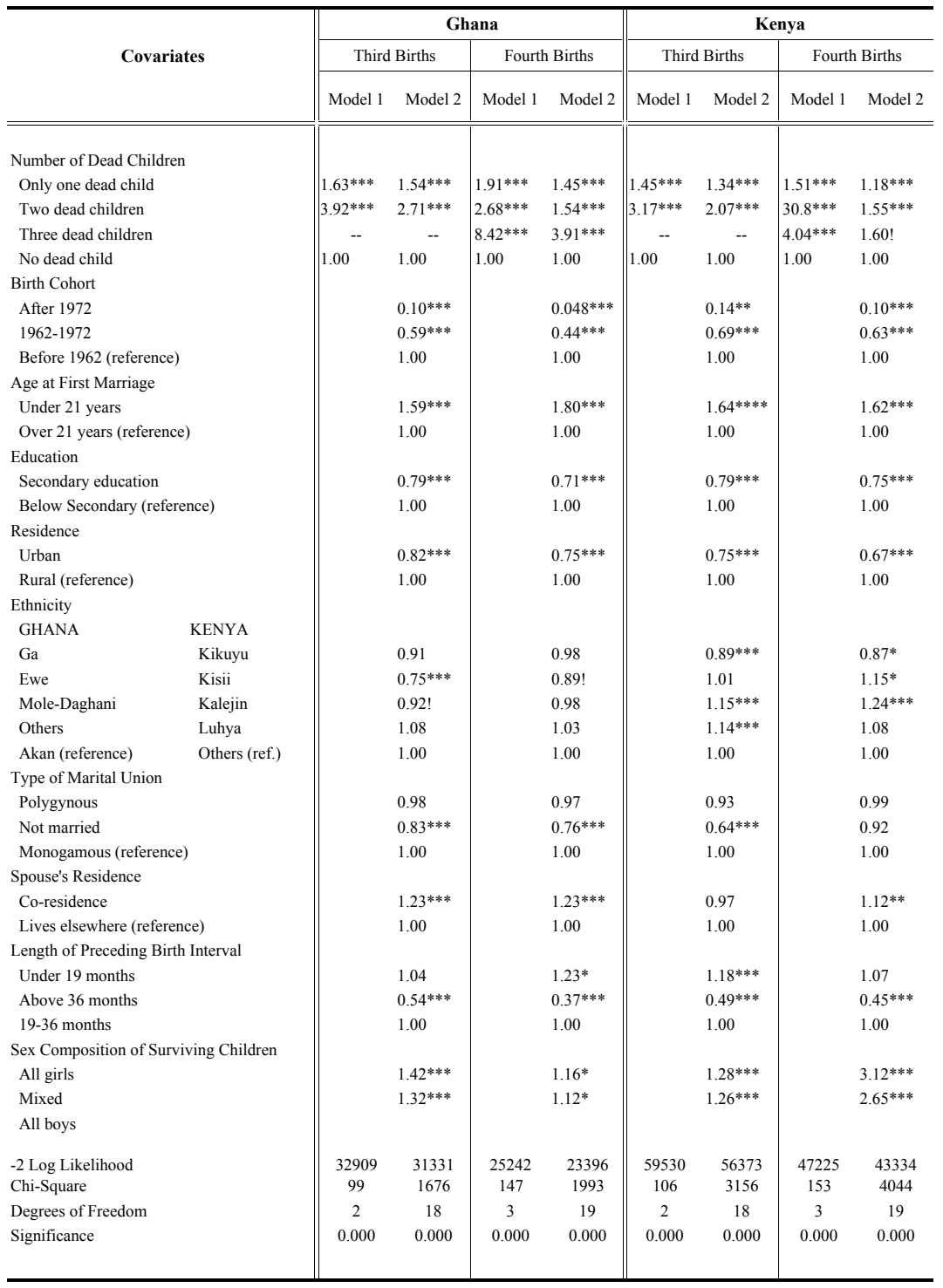


have not experienced any infant deaths, the risk of a fourth birth is 3.9 times higher among those with no surviving children, 1.54 for those with one surviving child and 1.46 among those with two surviving children as suggested by Model 2. Comparable patterns are seen among Kenyan women as Table 5 illustrates.

Besides the infant deaths, other covariates also have significant associations with the risk of births. The most important among these are birth cohort, age at first marriage, education, current place of residence, ethnicity, and the duration of the preceding interval. At all parities, younger women, urban residents and the highly educated are found to have a significantly lower risk of birth. The lower risk of births among the highly educated and urban women have been explained through socio-economic and cultural perspectives. The socioeconomic hypothesis examines the lower risk through the high use of modern contraception, education and labor force participation in the modern sector while the cultural perspective focuses on beliefs, values and norms regarding reproduction. From the socio-economic perspective, for instance, secondary educated women are more likely to be employed in formal occupations that generates mother-worker conflict.

The results also suggest that women whose surviving children were all girls had a higher risk of subsequent birth than those whose surviving children were all boys. This finding points to a gender preference and confirms some recent research in sub-Saharan Africa that alludes to son preference (e.g., Kuate Defo, 1998; Nyarko et al., 1999; Mace and Sear, 1997). Also significant are ethnic differences in the risk of births. In Ghana, the Mole-Dagbanis and Ewes tend to have lower risks compared with the Akans. In Kenya, the Kalenjins and Luhyas were consistently associated with higher risks and the Kikuyu with a lower risk. The ethnic differences in Ghana may be explained through socio-cultural factors such as the badu-gwan rites ${ }^{2}$, lineage systems, and the length of the postpartum abstinence period (Gyimah, 2003). Culturally, the postpartum period tends to be longer among the Ewes and the Mole-Dagbanis compared with the Akans. According to Gaisie (cited in Addai, 1999), a traditional Ewe is required to refrain from sex for 156 weeks following birth compared with 12 weeks for an Akan. In terms of lineage, the matrilocal residence of the Akans ensures more flexibility in childbearing and upbringing than the patrilocal residence of the Ewe and Mole-Dagbani. Given this flexibility, an Akan woman does not necessarily bear the overall cost of raising her children. As has been found elsewhere, cost-sharing in the up-bringing of children helps sustain high fertility (e.g., Isiugo-Abanihe, 1985). 


\section{Summary and Conclusion}

The findings in this study suggest a fair degree of intentional replacement behaviour. Women at any parity seem to exhibit higher risk of subsequent fertility when they have experienced child loss. The multivariate models also suggest that childhood mortality, in particular the death of the first child, has long term impact on reproductive behaviour. From a policy perspective, it is obvious that improvement in child survival programs could significantly improve the reproductive life of women by reducing fertility through both biological and behavioural processes.

The study is not without limitations. For example, a long term link between mortality and fertility may occur in ways that cannot be reduced to a simple causal effect of mortality on fertility. Women who live in areas with good health facilities, for instance, may have better access to family planning and better health services for their children, leading to lower fertility and mortality. Similarly, there may be durable patterns of behaviour that can be described as high fertility-high mortality strategies versus low fertility-low morality strategies that may lead to a statistical association that cannot be reduced to a simple unidirectional causal link.

There are additional research questions spurred by these findings. First, the effect of childhood deaths on reproductive behavior has also been explained through the insurance effect. This involves having births in excess of one's desired family size with the anticipation that the desired number of children will survive into adulthood by taking the prevailing mortality conditions into consideration. The higher a couple's perception of possible child loss, the greater will be the excess number of births (Lloyd and Ivanov, 1988). Measuring the insurance effect might require some measure of a couple's perception of prevailing childhood mortality conditions which could be achieved through a qualitative approach.

Indeed as Montgomery (1998) has pointed out, there is little understanding of the processes through which childhood mortality perceptions are formed. Are childhood mortality perceptions formed through direct personal experience, observed experience, or through social learning? To further this strand of research, there is a need for multi-level studies that explore the relationship among aggregate mortality trends, individual child survival experiences and individual reproductive behaviors. Also, large scale surveys such as the DHS are less useful in arriving at explanations of the observed patterns. The replacement hypothesis, for example, is fundamentally based on a micro decision model of action. Given the patriarchal context of the family and also 
Stephen Obeng Gyimah and Fernando Rajulton

the influence of the extended family in sub-Saharan Africa, it will be important to know who decides on replacement behaviour and when such decisions are made. Finally, given the limitations of our data, we are unable to assess the potential role of the HIV/AIDS epidemic on the child mortality- fertility (see Ainsworth, Filmer a nd Semali, 1998). These are issues that future research could examine.

\section{End Notes:}

1. We consider in this study up to fourth births because of sample size concerns.

2. This is custom where the wife's maternal family donates a ram to the husband on the birth of their $10^{\text {th }}$ child as a gesture and appreciation for the husband's significant addition to their matrilineal family.

\section{References:}

Addai, I.1999. "Ethnicity and Contraceptive Use in Sub-Saharan Africa: The Case of Ghana,” Journal of Biosocial Science 31(1): 105-120 .

Ainsworth, M., D. Filmer and I. Semali. 1998. "The Impact of AIDS on Individual Fertility: Evidence From Tanzania," in From Death to Birth: Mortality Decline and Reproductive Change. Mark R. Montgomery and Barney Cohen, (eds.). Washington, D.C.:

Allison, P.D. 1995. Survival Analysis Using the SAS System. Cary N.C.,: SAS Institute Inc.

Caldwell, J.C. 1982. Theory of Fertility Decline. London: Academic Press.

Callum, C., S. Farid, and M. Moussa. 1988. "Child loss and its impact on fertility," in Egypt: Demographic Responses to Modernization. A. Hallouda, S. Farid, and S. Cohcrane, (eds.). Cairo: Cental Agency for Public Mobilization and Statistics.

Cohen, B.1993. "Fertility levels, differentials, and trends, " in Demographic Change in sub-Saharan Africa. Karen Foote, Kenneth Hill, and Linda G. Martin, (eds.). Washington, D.C.: National Academy Press. 
Intentional Replacement of Dead Children in Sub-Saharan Africa:

Evidence from Ghana and Kenya

Cohen, B. and M. Montgomery. 1998. "Introduction," in From Death to Birth: Mortality Decline and Reproductive Change. Mark Montgomery and Barney Cohen, (eds.).Washington D.C.: National Academy Press.

Chowdhury, A.I., V. Fauvean and K.M.A. Aziz.1992. "Effects of child survival on contraceptive use in Bangladesh," Journal of Biosocial Science 24(4): 427-432.

Cox, D.R. 1972. "Regression Models and Life Tables (with discussion)," Journal of the Royal Statistical Society B34:187-220.

Ezeh, A.C. 1997. "Polygyny and reproductive behavior in sub-Saharan Africa: A contextual analysis," Demography 34(3): 355-368

Frankenberg, E. 1998. "The relationship between child mortality and subsequent fertility in Indonesia:1971-1991," in From Death to Birth: Mortality Decline and Reproductive Change. Mark R. Montgomery and Barney Cohen, (eds.). Washington D.C.,: National Academy Press

Gage, A. 1995. "An assessment of the quality of data on age at first union, first birth and the first sexual intercourse for Phase II of the Demographic and Health Surveys program," DHS Occasional Paper No. 4, June 1995. Macro International, DHS: Calverton, Maryland.

Garenne, M. and E. van de Walle. 1989. "Polygyny and fertility among the Sereer of Senegal,” Population Studies 43 (2): 267-283.

Grummer-Strawn, L., P. Stupp, and Z. Mei. 1998. "Effect of Child's Death on Birth Spacing: A Cross National Analysis," in From Death to Birth: Mortality Decline and Reproductive Change. Mark R. Montgomery and Barney Cohen, (eds.). Washington D.C.: National Academy Press.

Gyimah, S. O. 2001. Childhood Mortality and Reproductive Behavior in Ghana and Kenya: An Examination of Frailty and Non-frailty Models. Ph.D Dissertation, Faculty of Graduate Studies, The University of Western Ontario, London, Canada.

Gyimah, S. O. and R. Fernando. 2002. "The physiological effects of infant death on fertility: A comparative analysis of DHS data from Ghana and Kenya," Social Biology, 49(1-2): 44-57.

Gyimah, S.O. 2003. "A cohort analysis of the timing of first births in Ghana," Population Research and Policy Review, 22: 251-266. 
Stephen Obeng Gyimah and Fernando Rajulton

Isiugo-Abanihe, U. 1985. "Child fosterage in West Africa," Population and Development Review 11(1): 53-73.

Kuate Defo B. 1998. "Fertility response to infant and child mortality in Africa with special reference to Cameroon," in From Death to Birth: Mortality Decline and Reproductive Change. Mark R. Montgomery and Barney Cohen, (eds.). Washington, D.C.: National Academy Press.

LeGrand, T., T. Koppenhaver, N. Mondain and S. Randall. 2003. "Reassessing the insurance effect: A qualitative analysis of fertility behaviour in Senegal and Zimbabwe," Population and Development Review 29(3): $375-404$

Lesthaeghe, R. (ed.) 1989. Reproduction and Social Organization in SubSaharan Africa. Berkeley: UCLA Press.

Llyod, C. and S. Ivanov.1988. "The effects of improved child survival on family planning practice and fertility," Studies in Family Planning 19(3): 141-161.

Mace, A. 1996. "When to have another baby: A dynamic model of reproductive decision making and evidence from Gabbra pastoralists," Ethology and Sociobiology 17: 263-273.

Mace, A. and R. Sear. 1997. "Birth interval and the sex of children in a traditional African population: An evolutionary analysis," Journal of Biosocial Science 29: 499-507.

Martin, T. 1995. "Women's education and fertility: Results from 26 Demographic and Health Surveys," Studies in Family Planning 26: 187-202.

Meekers, D. 1992. "The Process of Marriage in African Societies: A Multiple Indicator Approach," Population and Development Review, 18(1): 6178.

Mensch, B. 1985. "The effect of child mortality on contraceptive use in Columbia, Costa Rica and Korea," Population Studies 39(2): 309-327. 
Intentional Replacement of Dead Children in Sub-Saharan Africa:

Evidence from Ghana and Kenya

Montgomery, M.R. 1998. "Learning and Lags in Mortality Perceptions," in From Death to Birth: Mortality Decline and Reproductive Change. Mark R. Montgomery and Barney Cohen, (eds.). Washington, D.C.: National Academy Press

Montgomery, M.R. and B. Cohen (eds.)1998. From Death to Birth: Mortality Decline and Reproductive Change. Washington, D.C.: National Academy Press.

Nyarko, P., N. Madise and I. Diamond.1999. Infant mortality and the pace of childbearing in Ghana: Some evidence of son preference. Paper presented at the Third African Population Conference, Durban South Africa December 6-10.

Oheneba-Sakyi, Y. and B. K. Takyi. 1997. "Effects of couples' characteristics on contraceptive use in sub-Saharan Africa: The Ghanaian example," Journal of Biosocial Science 29: 33-49.

Preston, S.H. (ed.) 1978. The Effects of Infant and child Mortality on Fertility. New York: Academic Press.

Rahman, M. 1998. "The effect of child mortality on fertility regulation in rural Bangladesh," Studies in Family Planning 29(3): 261-281.

Trussell, J., E. van de Walle and F. van de Walle.1989. "Norms and behavior in Burkinabe fertility," Population Studies 43 (3): 429-454.

Westoff, C.F. 1992. "Age at Marriage, Age at first Birth and Fertility in Africa," World Bank Technical Paper Number 169. Washington, D.C.: The World Bank.

Wolpin, K.J. 1998. “ The Impact of Infant and Child Mortality Risk on Fertility," in From Death to Birth: Mortality Decline and Reproductive Change. Mark R. Montgomery and Barney Cohen, (eds.). Washington, D.C.: National Academy Press 